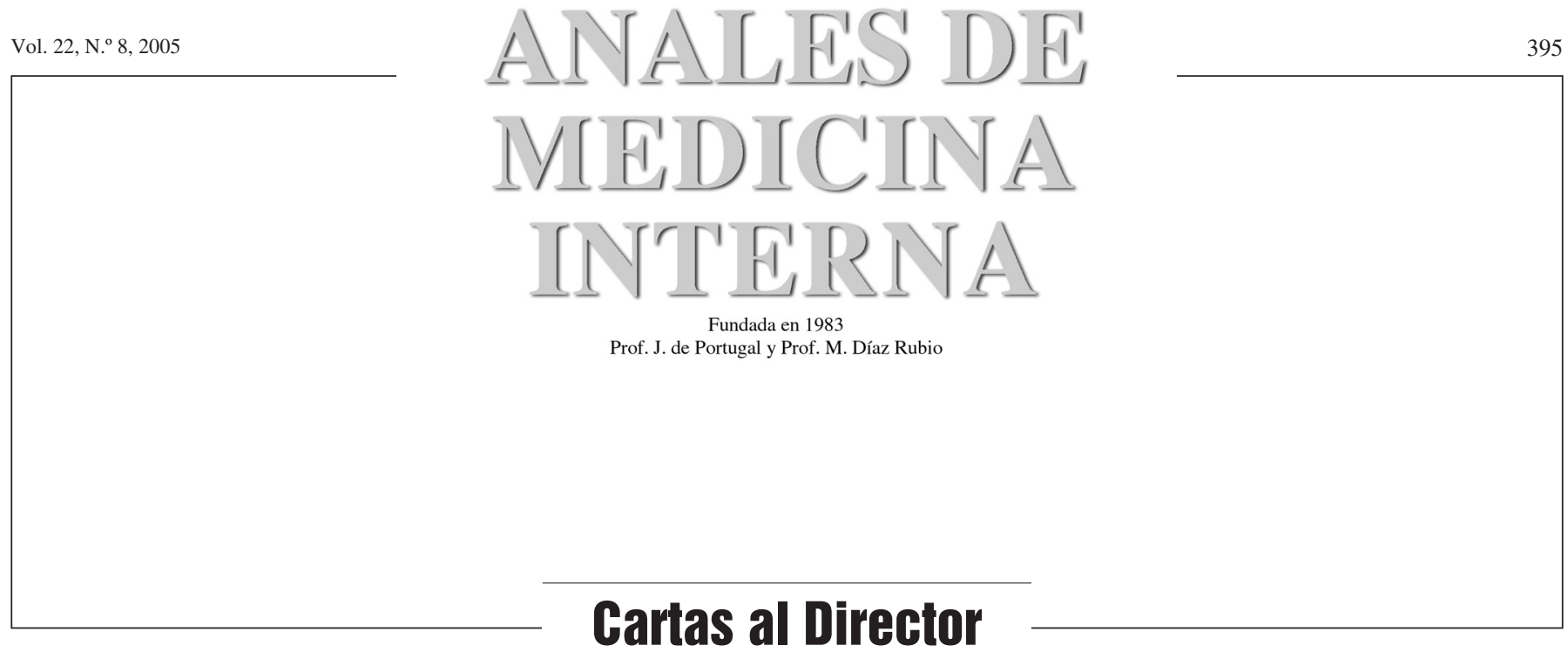

\section{Insuficiencia renal por sulfadiazina en paciente VIH con toxoplasmosis cerebral}

\section{Sr. Director:}

La toxoplasmosis cerebral (TC) era (y sigue siendo) la infección oportunista más frecuente del SNC en los pacientes con sida. La incidencia de la TC es proporcional a la prevalencia de la infección latente en la población. Así, mientras en Europa la prevalencia era superior al $50 \%$ y el $25-50 \%$ desarrollaban la enfermedad, en los EE.UU., donde la prevalencia es del 10$40 \%$, la incidencia era claramente inferior (1). En el 50-70\% casos el diagnóstico de TC es posterior al diagnóstico de sida (2). La mortalidad continúa siendo alrededor de un 20-25\% y casi la mitad de los pacientes quedan con secuelas neurológicas. Es por ello que se recomienda la profilaxis primaria a pacientes con riesgo, considerándose estos a los seropositivos con cifras de CD4+ por debajo de 100/ml (4). El régimen profiláctico primario de primera elección sigue siendo, en ausencia de contraindicaciones, el cotrimoxazol. En un estudio multicéntrico quedó demostrado que la profilaxis primaria puede retirarse con seguridad en pacientes en recuperación con CD4+ mayor de 200/ml (al menos durante 3-6 meses) y manteniendo una carga viral menor de 5.000 copias/ml (5). El tratamiento de elección de la TC aguda es la combinación de sulfadiazina y pirimetamina, asociando ácido folínico, durante 6-8 semanas (6). La respuesta clínica es favorable en el 70-80\% de pacientes (3). La terapéutica con corticoides se reserva para las lesiones que cursen con edema o/y efecto de masa con síntomas clínicos y peligro de enclavamiento cerebral. En alrededor del 20-40\% de los casos aparecen efectos adversos al tratamiento (7). La alternativa en pacientes que no toleran la sulfadiazina es el empleo de clindamicina. En estudios prospectivos comparando sulfadiazina-pirimetamina frente a clindamicina-pirimetamina no se observaron diferencias significativas en cuanto a eficacia o toxicidad de ambas pautas (8). Uno de estos efectos adversos de la sulfadiazina lo constituye la nefrotoxicidad por depósito de cristales de sulfadiazina en túbulos renales.

Presentamos el caso de una mujer de 39 años diagnosticada previamente de VIH grupo-C3, que en la actualidad no sigue tratamiento antiretroviral con episodio previo, 5 años atrás, de toxoplasmosis cerebral. Refiere cefalea progresiva acompañada de pérdida de fuerza en hemicuerpo derecho de predominio braquial acompañada de sensaciones parestésicas, desviación comisural a la izquierda, disartria y fiebre de hasta $38,5^{\circ}$. En la exploración física se objetiva una hemiparesia derecha de predominio braquial (ESD 3+/5; EID 4+/5) con hemihipoestesia del mismo lado, hiporreflexia derecha con hemisomatognosia del mismo lado y RCP extensor también derecho. En la TAC craneal se observa un área hipotensa en núcleos básales izquierdos con desplazamiento del sistema ventricular, y, tras contraste, imagen nodular de unos $3 \mathrm{~cm}$ y otras de menor tamaño, todas hipercaptantes. En la analítica de sangre leucocitosis con desviación izquierda y linfocitos totales de 395 cels/micrL con 15 CD4; la creatinina es de 0,9 $\mathrm{mg} / \mathrm{dL}$ y la urea de $17 \mathrm{mg} / \mathrm{dL}$. Conocidos los antecedentes y ante la alta sospecha de TC por los datos clínico-radiológicos, se inicia tratamiento empírico con la combinación de sulfadiazina-pirimetamina. A las 48 horas se constata una clara mejoría clínica del déficit sensitivo-motor. En la TAC craneal de control a la semana se observa mejoría radiológica de las lesiones cerebrales. Sin embargo, a los 5 días, comienza con náuseas, vómitos, oliguria e intolerancia a la ingesta y a la medicación oral. Se solicita analítica urgente de sangre y de orina, y ecografía renal. En plasma se objetiva una creatinina de $8,1 \mathrm{mg} / \mathrm{dL}$ y una urea de $137 \mathrm{mg} / \mathrm{dL}$. El estudio ecográfico resulta normal. Se decidió sustituir la sulfadiazina por clindamicina, y se iniciaron medidas de rehidratación para conseguir diuresis diarias entre 2-3 litros. En la analítica solicitada a los cinco días, la creatinina en plasma es de 1,1 $\mathrm{mg} / \mathrm{dL}$ y la urea de $28 \mathrm{mg} / \mathrm{dL}$.

La incidencia en el tratamiento de la TC, en pacientes VIHpositivos, de insuficiencia renal es de $2-7,5 \%$ (dos veces la incidencia en pacientes VIH-negativos)(9). La depleción de volumen ya sea por disminución de la ingesta de líquidos o por aumento de pérdidas (fiebre, diarrea o vómitos), la administración de radio contraste y la concurrencia de tratamiento con drogas que favorecen la acidificación del $\mathrm{pH}$ urinario constituyen factores de riesgo para el depósito de cristales de sulfadiazina; así mismo la hipoalbuminemia favorece el aumento de los niveles séricos de sulfadiazina (10). La cristalización del fármaco depende, fundamentalmente, de su concentración en la orina y del $\mathrm{pH}$ urinario, por lo que la dosis administrada y la deshidratación son los factores desencadenantes más importantes. Aquellos factores que contribuyen a mantener un bajo volumen intravascular, diuresis diarias menores de 2 litros y $\mathrm{pH}$ urinarios menores de 7 , favorecen la menor solubilidad de la sulfadiazina, la acetilación de sus metabolitos (son insolu- 
bles) y su depósito en los túbulos renales. El diagnóstico puede establecerse realizando análisis de sangre, donde encontramos elevación de urea y creatinina, y confirmarse con una analítica de orina donde observamos un $\mathrm{pH}$ menor de 6 , hematuria y depósito de cristales de $\mathrm{N}$-acetilsulfadiazina en el sedimento. En la ecografía renal podemos observar imágenes ecogénicas compatibles con nefrolitiasis o, más frecuentemente, hallazgos normales. El cuadro clínico puede aparecer tanto al inicio (más frecuente) como a lo largo del tratamiento y suele caracterizarse por dolor abdominal tipo cólico, náuseas acompañadas o no de vómitos, hematuria y, si persiste, oliguria e insuficiencia renal aguda (9). El tratamiento consiste en la hidratación adecuada manteniendo diuresis diaria de 2 o más litros y conseguir mantener un $\mathrm{pH}$ urinario mayor de 7 . En los casos graves (acidosis severa, hipercaliemia y uremia severa) con fallo renal agudo, estaría indicado el tratamiento con hemodiálisis (10). No existen estudios que demuestren la necesidad de suspender el tratamiento con sulfadiazina, aunque desde el punto de vista práctico, se aconseja disminuir dosis o incluso cambiar la terapia iniciada que incluye la sulfadiazina por la combinación clindamicina-pirimetamina. Una vez resuelto el episodio de cristaluria, nefrolitiasis e insuficiencia renal, si se ha producido, y corregido los parámetros analíticos, la reintroducción de la sulfadiazina debe ser evaluada individualmente.

Podemos concluir que la aparición de depósito de cristales, nefrolitiasis y/o insuficiencia renal, al inicio o durante el tratamiento con sulfadiazina de la TC en los pacientes con sida, no son infrecuentes y deben ser tenidos en cuenta dado que podemos aplicar medidas preventivas. Estas medidas consisten en una adecuada hidratación para conseguir diuresis de 2-3 litros diarios y mantener un $\mathrm{pH}$ urinario mayor de 7 . Con ello podemos evitar, prácticamente en la totalidad de casos, la aparición de estos efectos adversos y de sus posibles complicaciones. No está claramente demostrado que sea necesaria la suspensión y/o la sustitución de sulfadiazina-pirimetamina por la combinación clindamicinapirimetamina para continuar el tratamiento de la TC durante 6-8 semanas. Existen estudios recientes donde no se observaron datos que sugiriesen contraindicación de continuar tratamiento con sulfadiazina una vez resuelto el episodio. Sin embargo, la experiencia clínica aconseja la suspensión del tratamiento con sulfadiazina, y su sustitución, en caso de aparecer las complicaciones descritas, y valorar individualmente la reintroducción de la sulfadiazina, una vez resueltas dichas complicaciones, en los pacientes seropositivos con toxoplasmosis cerebral.

M. Solano Remírez, A. S. Oliván Ballabriga, G. M. da Costa Rodríguez, M. T. Álvarez Frías, C. González Arencibia

Servicio de Medicina Interna. Hospital de Navarra. Pamplona

1. Clumeck N. Some aspects of the epidemiology of toxoplasmosis and Pneumocystis in AIDS in Europe. Eur J Clin Microbiol Infect Dis 1991; 10: $177-8$

2. Porter S, Sande M. Toxoplasmosis of the central nervous system in the acquired inmunodeficiency syndrome. N Engl J Med 1992; 327: 16438.

3. Ciricillo $\mathrm{S}$, Rosemblum M. Use of CT and MR imaging to distinguish intracranial lesions and to define the need for biopsy in AIDS patients. J Neurosurg 1990; 73: 720-4.

4. Leport C, Chêne G, Morlath Ph, et al. Pyrimethamine for primary of toxoplasmic encephalitis in patients with human immunodeficiency virus infection: a double-blind, randomized trial. J Infect Dis 1996; 173: $91-7$.

5. Miro J, López J, Podzamczer D, et al. Discontinuation of primary or secondary Toxoplasma gondii prophylaxis is safe in VIH-1-infected patients after immunological recovery with HAART. Final results of the
GESIDA 04/98-B study. 40th ICAAC. Toronto, septiembre 2000 (presentación L-16).

6. Katlama C, De Wit S, O'Doherty E, et al. Treatment of toxoplasmosis in AIDS patients. Clin Infect Dis 1996; 22: 268-75.

7. Wong S, Israelski D, Remington J. AIDS-associated toxoplasmosis. En: Sande M, Volberding P (eds.). The medical management of AIDS. 4. ${ }^{\mathrm{a}}$ ed. Philadelphia: WB Saunders 1995: 460-93.

8. Dannemann B, McCuthan J, Israelski D, et al. Treatment of toxoplasmic encephalitis in patients with AIDS: A randomized trial comparing pyrimethamine plus clindamycin to pyrimethamine plus sulphadiazine. The California Collaborative Treatment Group. Ann Intern Med 1992; 116: 33-43.

9. Becker K, Jablonowski H, Haussinger D. Sulfadiazine-associated nephrotoxicity in patients with adquired immunodeficiency syndrome. Medicine-Baltimore 1996; 75: 185-94.

10. Don B, Rodriquez RA, Humphreys MH. Acute renal failure associated with pigmenturia or crystal deposits. In: Schrier RW, Gottschalk CW, editors. Diseases of the kidney. 6th ed. Boston: Little, Brown, 1997.

\section{Crisis convulsiva por bupropion}

\section{Sr. Director:}

Dentro de los tratamientos empleados para la deshabituación al tabaquismo, en los últimos años ha demostrado ser eficaz un medicamento (bupropion) ampliamente empleado en el tratamiento de los trastornos depresivos (1). Es conocido y aceptado que los estados de ánimo y del humor producen importantes efectos en la motivación para consumir nicotina. Se ha visto que los fumadores son más propensos a presentar síntomas propios de los trastornos de afectividad que los no fumadores (2). Los síntomas de dependencia a la nicotina se correlacionan con la intensidad de síntomas en la esfera de la afectividad, por lo que el estado de ánimo bajo ó negativo conlleva a una mayor disponibilidad para comenzar a fumar y mayor dificultad para el abandono del hábito tabáquico, pudiendo estar relacionado con alteraciones en la actividad dopaminérgica cerebral (4). Clásicamente, los derivados de la nicotina, en forma de chicles ó de parches, han demostrado su eficacia en la deshabituación tabáquica multiplicando las tasas de abandono del hábito conseguidas con placebo, aunque en un porcentaje no despreciable de estos, vuelven a recaer. Cada año, aproximadamente unos 20 millones de fumadores estadounidenses intentan dejar el hábito, pero sólo un $6 \%$ de los que lo intentan, consiguen, a largo plazo, abandonarlo. En un estudio a doble ciego y controlado con placebo en 1999, DE Jorenby y cols. demostraron que el tratamiento con bupropion solo ó asociado a parches de nicotina alcanzó, a largo plazo, tasas de deshabituación significativamente superiores a las obtenidas con parches de nicotina solos o placebo, siendo las tasas de abstinencia con terapia combinada superiores a la conseguida con bupropion solo, pero no alcanzando éstas una significación estadística (3). La mayoria de los efectos adversos del bupropion son, en general, de carácter leve, y dosis-dependientes (cefalea, insomnio, sequedad de boca...); entre los de carácter grave destaca, por su importancia clínica, las crisis convulsivas.

Presentamos el caso de una mujer de 20 años de edad en cuyos antecedentes personales podemos destacar un hábito tabáquico importante (más de 20 cigarrillos al día) en tratamiento de deshabituación desde hace 40 días con bupropion 1 comprimido/12 h; no traumatismo craneoencefálico previo. Los antecedentes familiares carecen de interés. Presentó episodio de pérdida de conciencia brusco con caída al suelo, seguido de movimientos convulsivos tónico-clónicos generalizados asociado a mordedura de 